\title{
Meandering effect for evaluation of roughness coefficients in open channel flow
}

\author{
K. K. Khatua, K. C. Patra \& P. Nayak \\ Department of Civil Engineering, National Institute of Technology, India
}

\begin{abstract}
During uniform flow in an open channel, the resistance is dependent on a number of flow and geometrical parameters. The usual practice in one dimensional flow analysis is to select an appropriate value of roughness coefficient for evaluating the carrying capacity of natural channel. This value of roughness is taken as uniform for the entire surface and for all depths of flow. However, it is observed that the resistance coefficients for meandering channels are found to vary with flow depths, aspect ratio, slope and sinuosity and are all linked to the stage-discharge relationships. Although much research has been done on Manning's $n$ for straight channels, a last word has not been spoken on the roughness values for meandering channels. An investigation concerning the variation of roughness coefficients for meandering channels with slope, sinuosity and geometry are presented. The loss of energy in terms of Darcy-Weisbach coefficient $f$ is evaluated. A simple equation for roughness coefficient based on dimensional analysis is modeled and tested with the recent experimental data. The method gives discharge results that are quite comparable to that of the observed values as well as with other published data.

Keywords: aspect ratio, bed slope, boundary shear, Darcy-Weisbach coefficient, dimensional analysis, meandering channel, flow resistance, Sinuosity $\left(S_{r}\right)$, stagedischarge relationship.
\end{abstract}

\section{Introduction}

The energy loss in a meandering channel is influenced by the channel and flow parameters and is assumed to be lumped into a single value that is manifested in the form of a single resistance coefficient. Wrong estimation of resistance coefficient can either underestimate or overestimate the discharge carrying 
capacity of a channel. A number of researchers have studied the phenomenon of flow mostly in straight channels and proposed their methods for estimating the river discharge. Sellin [18], Shiono et al. [19], Patra and Kar [16], Patra and Khatua [17], Khatua [12] etc. have shown that the structure of the flow is surprisingly more complex for meandering channels as compared to that of straight channels. Meandering channels have components of velocity in all the three directions which are significant for the analysis. Consequently, the use of design methods based on straight channels is inappropriate when applied to meandering channels. Determination of suitable value of roughness coefficient for a given channel is therefore the most significant factor for evaluating the actual carrying capacity of natural channels. In general, the classical methods of discharge estimations are normally based on flow in a straight channel. These are essentially flawed when applied to meandering channels.

An investigation into the variation of resistance coefficients in a meandering channels resulting from boundary friction, secondary flow, turbulence, sinuosity, geometry and other factors has been presented. The energy loss is manifested in the form of variation of resistance coefficients of the channel with depth of flow. In the present study, it is attempted to formulate the models for predicting discharge by selecting a proper value of roughness coefficient in terms of DarcyWeisbach $f$. The results of the present model are compared well with other established methods.

\section{Previous works}

Flow in meandering channel is considerably more complex than straight channel due to its continuous stream wise variation of radius of curvature which is in the state of either development or decay or both. The US Army Corps of Engineers (Hydraulic [8]) conducted a series of stage-discharge experiments in meandering channels at the Waterways Experiments Station in Vicksburg. The main purpose of these experiments was to investigate the effect of the geometric parameters on the conveyance capacity of compound meandering channels. The basic approach proposed by Cowan [6] was that

$$
n=\left(n_{b}+n_{1}+n_{2}+n_{3}+n_{4}\right) m
$$

where $n_{b}=$ base $n$ value; $n_{l}=$ addition for surface irregularities; $n_{2}=$ addition for variation in channel cross section; $n_{3}=$ addition for obstructions; $n_{4}=$ addition for vegetation; $m=$ ratio for meandering. Equation (1) was modified by Arcement and Schneider [1]. Suggested values for Manning's $n$ are tabulated by Chow [5]. The Soil Conservation Service (SCS) method for selecting roughness coefficient values for channels [7] accounted for meander losses by adjusting the base value of Manning's $n$ on the basis of sinuosity $(s)$, as follows:

$$
\begin{gathered}
\frac{n^{\prime}}{n}=1.0 \text { for longitudinal slope }(S)<1.2 \\
\frac{n^{\prime}}{n}=1.15 \text { for } \quad 1.2 \leq S<1.5
\end{gathered}
$$




$$
\frac{n^{\prime}}{n}=1.15 \text { for } S \geq 1.5
$$

where $S=$ channel gradient $n^{\prime}=$ the adjusted value; and $n=$ the basic value. Sinuosity is defined as the ratio of the length along the channel centre line between two points to the straight line distance between the points. Because $n$ is proportional to $f^{1 / 2}$ the adjustment should be squared when using the DarcyWeisbach equation. Visual estimation of $n$ values can be made at each site using Barne's [2] guideline.

Chang [3] investigated energy expenditure and proposed an analytical model for obtaining the energy gradient, based on fully developed secondary circulation for wide rectangular sections. Jarrett [11] developed a model to determine Manning's $n$ for natural high gradient channels having stable bed and in-bank flow without meandering coefficient. He proposed, a value for Manning's

$$
n=\frac{0.32 S^{0.38}}{R^{0.16}}
$$

where $S$ is the channel gradient, $R$ the hydraulic radius in meters. The equation was developed for natural main channels having stable bed and bank materials (boulders) without bed rock. It was intended for channel gradients from $0.002-$ 0.04 and hydraulic radii from $0.15-2.1 \mathrm{~m}$, although Jarrett noted that extrapolation to large flows should not be too much. Arcement and Schneider [1] modified Cowan method and was designed specifically to account for selecting $n$ values for natural channels and flood plains resistance. In the modified equation the coefficients were taken as $n_{b}=$ a base value $n$ for the floodplain's natural bare soil; $n_{1}=$ a correction factor for the effect of surface irregularities on floodplain (range $0-0.02) ; n_{2}=$ a value for variation in channel shape and size of the floodplain cross section; $n_{3}=$ a value for obstructions on the floodplain (range 0 $0.03) ; n_{4}=$ a value for vegetation on the floodplain (range $\left.0.001-0.2\right) ; m=\mathrm{a}$ correction factor for sinuosity of the floodplain $=1.0$. Each variable values were selected from tables in Arcement and Schneider [1]. The step nature of the SCS recommendation introduces discontinuities at the limits of the defined sinuosity ranges, with consequent ambiguity and uncertainty. To overcome the problem the relationship was linearised, known as the Linearised SCS (LSCS) method. The proposed the value of Manning's $n$ using two cases of sinuosity $\left(S_{r}\right)$, i.e. $\mathrm{S}_{\mathrm{r}}$ $<1.7$ and $S_{r} \geq 1.7$.

James and Wark [10] reviewed the various methods for bend loss in meandering channel proposed by different investigators. He proposed some new methods accounting for additional resistance due to bend by suitable modifications of previous methods. His modified method predicted well the stage discharge relationships for meandering channels. Shiono et al. [19] reported the effect of bed slope and sinuosity on discharge of meandering channel. Basing on dimensional analysis, an equation for the conveyance capacity was derived, which was subsequently used to obtain the stage-discharge relationship for meandering channels. It was found that the channel discharge increased with increase in bed slope and it decreased with increase in sinuosity for the same channel. Maria and Da Silva [14] expressed the friction factor of 
rough turbulent meandering flows as the function of sinuosity and position (which is determined by, among other factors, the local channel curvature). They validated the expression by the laboratory data for two meandering channels of different sinuosity. The expression was found to yield the computed vertically averaged flows that were in agreement with the flow pictures measured for both large and small values of sinuosity. Patra and Kar [16], Patra and Khatua [17], Khatua [12] etc., have shown that Manning's $n$ not only denotes the roughness characteristics of a channel but also the energy loss in the flow. Lai Sai Hin et al. [13] expressed that estimation of discharge capacity in river channels was complicated by variations in geometry and boundary roughness.

The present research work is intended to study the stage-discharge relationship with the variation of channel roughness, geometry and sinuosity in meandering channels using dimensional analysis. This should be useful in better understanding of the mechanism of flow in a meandering channel and so for the solution of many practical problems.

\section{Experimental setup}

The present research uses both meandering and straight experimental channels fabricated inside the tilting flumes separately in the Fluid Mechanics and Hydraulics Engineering Laboratory of the Civil Engineering Department, at the National Institute of Technology, Rourkela. Observation are made for two straight channels, one of rectangular cross section (Type-I) and another of trapezoidal cross section (Type-II). The other two channels are Type-III and Type-IV respectively, consisting of meandering channel. The tilting flumes are made out of metal frame with glass walls at the test reach. The flumes are made tilting by hydraulic jack arrangement. Inside each flume, separate meandering/straight channels are cast using $5 \mathrm{~mm}$ thick Perspex sheets. To facilitate fabrication, the whole channel length has been made in blocks of $1.20 \mathrm{~m}$ length each. The photo graphs of Type-IV experimental channels with

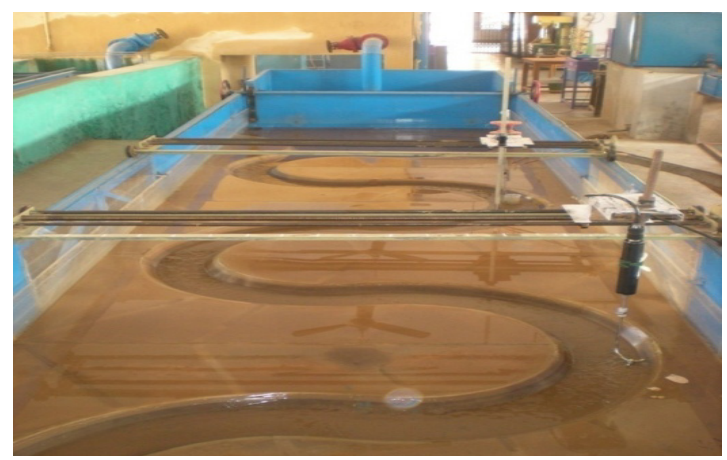

Photo 1: Type-IV experimental channel with measuring equipment. 
measuring equipment taken from the downstream side is shown in Photo 1 and the sectional plan view is shown in Fig. 1. The detailed geometrical features of all the experimental channels are given in Table 1.

Water is supplied to the experimental setup by a recirculating system. Two parallel pumps are used to pump water from an underground sump to the overhead tank. From the over head tank, water is led to a stilling tank located at the upstream of the channel. A series of baffle walls between the stilling tank and channels are kept to reduce turbulence of the incoming water. At the end of the experimental channel, water is allowed to flow through a tailgate and is collected in a masonry volumetric tank, from where it is allowed to flow back to the underground sump. From the sump, water is pumped back to the overhead tank, thus setting a complete re-circulating system of water supply for the experimental channel. The tailgate helps to establish uniform flow in the channel.

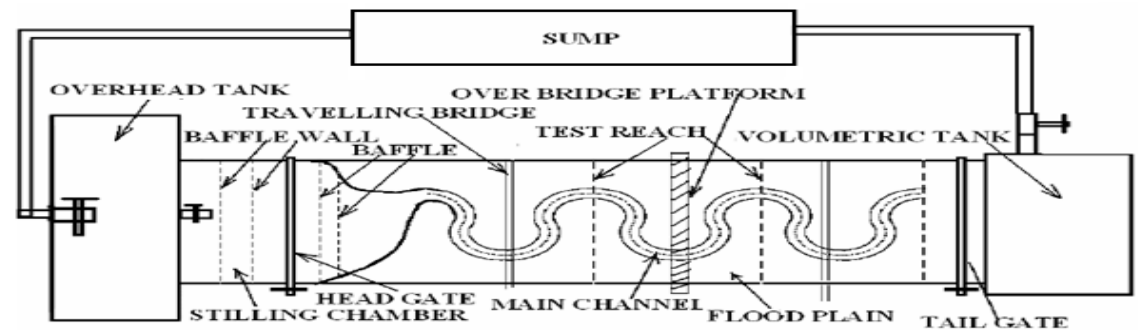

Figure 1: Plan view of Type-IV meandering channel within experimental flume.

Table 1: Details of geometrical parameters of the experimental channels.

\begin{tabular}{|c|c|c|c|c|c|}
\hline $\begin{array}{l}S l \\
\text { ho. }\end{array}$ & Item description & Type-I & Type-II & Type-III & Type-IV \\
\hline 1 & Channel Type & Straight & Straight & Meandering & Meandering \\
\hline 2 & $\begin{array}{l}\text { Wave length in } \\
\text { down valley } \\
\text { direction }\end{array}$ & - & - & $400 \mathrm{~mm}$ & $2185 \mathrm{~mm}$ \\
\hline 3 & Amplitude & - & - & 162 & $685 \mathrm{~mm}$ \\
\hline 4 & $\begin{array}{l}\text { Geometry of Main } \\
\text { channel section }\end{array}$ & Rectangular & $\begin{array}{c}\text { Trapezoidal } \\
\text { (side slope } 1: 1 \text { ) }\end{array}$ & Rectangular & $\begin{array}{c}\text { Trapezoidal } \\
\text { (side slope 1:1) }\end{array}$ \\
\hline 5 & $\begin{array}{l}\text { Nature of surface } \\
\text { of bed }\end{array}$ & $\begin{array}{l}\text { Smooth and } \\
\text { rigid bed }\end{array}$ & $\begin{array}{l}\text { Smooth and } \\
\text { rigid bed }\end{array}$ & $\begin{array}{l}\text { Smooth and } \\
\text { rigid bed }\end{array}$ & $\begin{array}{l}\text { Smooth and } \\
\text { rigid bed }\end{array}$ \\
\hline 6 & Channel width (b) & $120 \mathrm{~mm}$ & $\begin{array}{l}120 \mathrm{~mm} \text { at bottom } \\
\text { and } 280 \mathrm{~mm} \text { at top }\end{array}$ & $120 \mathrm{~mm}$ & $\begin{array}{c}120 \mathrm{~mm} \text { at } \\
\text { bottom and } \\
280 \mathrm{~mm} \text { at top }\end{array}$ \\
\hline 7 & $\begin{array}{l}\text { Bank full depth of } \\
\text { channel }\end{array}$ & $120 \mathrm{~mm}$ & $80 \mathrm{~mm}$ & $120 \mathrm{~mm}$ & $80 \mathrm{~mm}$ \\
\hline 8 & $\begin{array}{l}\text { Bed Slope of the } \\
\text { channel }\end{array}$ & 0.0019 & 0.003 & 0.0031 & Varying \\
\hline 9 & Sinuosity & 1.00 & 1.00 & 1.44 & 1.91 \\
\hline 10 & Flume size & $\begin{array}{c}0.45 m \times 0.4 m \\
\times 12 m \text { long } \\
\end{array}$ & $\begin{array}{r}2.0 m \times 0.6 m \\
\times 12 m \text { long } \\
\end{array}$ & $\begin{array}{c}0.6 m \times 0.6 m \\
\times 12 \mathrm{~m} \text { long } \\
\end{array}$ & $\begin{array}{r}2.0 m \times 0.6 m \\
\times 12 m \text { long } \\
\end{array}$ \\
\hline
\end{tabular}


Water surface slope measurement is carried out using a pointer gauge fitted to the travelling bridge operated manually having least count of $0.1 \mathrm{~mm}$. Point velocities are measured using a 16-Mhz Micro ADV (Acoustic Doppler Velocity-meter) at a number of locations across the predefined channel section. Guide rails are provided at the top of the experimental flume on which a travelling bridge is moved in the longitudinal direction of the entire experimental channel. The point gauge and the micro-ADV attached to the travelling bridge can also move in both longitudinal and the transverse direction of the experimental channel at the bridge position. The micro-ADV readings are recorded in a computer placed besides the bridge. As the ADV is unable to read the data of upper most layer (up to $5 \mathrm{~cm}$ from free surface), a micro -Pitot tube of $4 \mathrm{~mm}$ external diameter in conjunction with suitable inclined manometer are used to measure velocity and its direction of flow at the pre defined points of the flow-grid. A flow direction finder is also used to get the direction of maximum velocity with respect to the longitudinal flow direction. The Pitot tube is physically rotated normal to the main stream direction till it gives maximum deflection of manometer reading. The angle of limb of Pitot tube with longitudinal direction of the channel is noted by the circular scale and pointer arrangements attached to the flow direction meter. Discharge in the channel is measured by the time rise method in the measuring tanks located at the downstream end of the experimental channel. All observations are recorded in the central test reach for straight channel of Type-I and Type-II and at one of the bend apex of Type-III and type-IV meandering channels.

The results of experiments concerning the flow and roughness variations of meandering channels are presented in this chapter. Analysis of results is done for roughness coefficients and distribution of boundary shear in a meandering channel. The overall summaries of experimental runs are given in Table 1.

\section{Experimental results}

\subsection{Stage-discharge variations for meandering channels}

Flow depths in the experimental channel runs are so maintained that the water surface slope becomes parallel to the valley slope. At this stage, the energy losses are taken as equal to potential energy input. In all the experimental runs this simplified approach has been tried to achieve. This stage of flow is taken as normal depth, which can carry a particular flow only under steady and uniform conditions. The stage discharge curves plotted for different bed slopes for particular sinuosities of channel are shown in Fig. 2. The discharge increases with an increase in bed slope for the same stage.

\subsection{Variation of reach averaged longitudinal velocity $U$ with depth of flow}

Plots between the reach averaged velocity $U$ versus flow depth for all the experimental channels for the four types of channels are shown in Fig. 3. From the figure it can be seen that for all the channels, the increase in reach averaged 


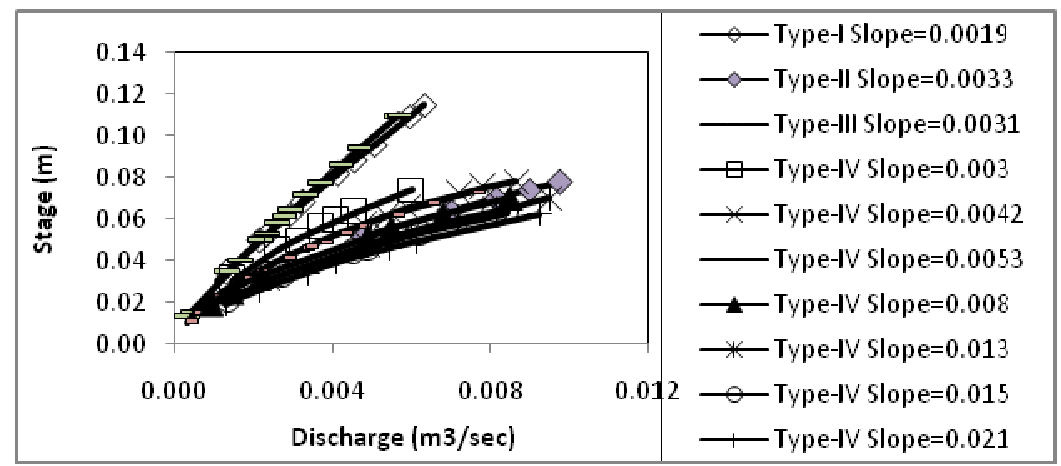

Figure 2: $\quad$ Stage discharge variations in open channel flow.

longitudinal velocity of flow is nearly in accordance with the increase in depth of flow. For all flow conditions, the rate of increase of velocity with flow depth is higher for the sinus channel of Type-IV and lower for straight channel of Type-I. This is mainly due to their large differences in the longitudinal bed slopes. The slope of the channel is an important parameter influencing the desired driving force. As for higher slopes (Type-IV, slope $=0.021,0.015,0.013$ ) in a particular channel there is increase in the rate of velocity with flow depth.

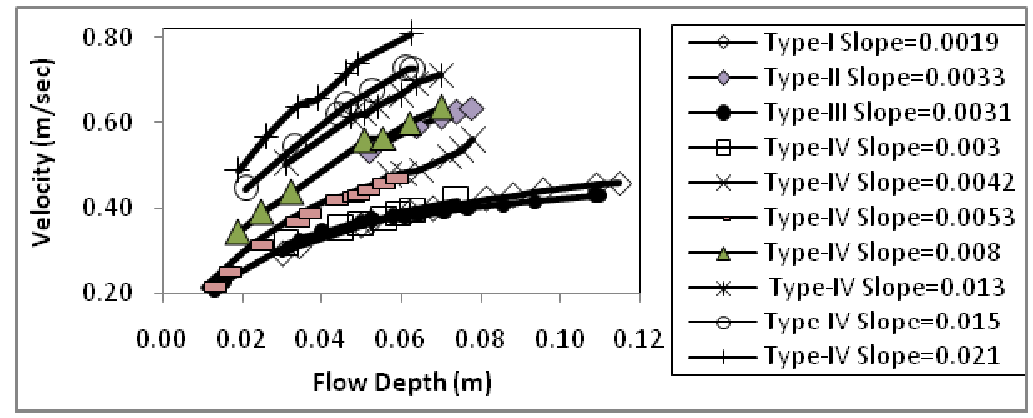

Figure 3: $\quad$ Variations of velocity with flow depth in open channel flow.

\subsection{Roughness coefficients in meandering channel flow}

Distribution of energy in a channel section is an important aspect that needs to be addressed properly. While using Darcy-Weisbach equation, selection of a suitable value of roughness coefficient $f$ is the single most important parameter for the proper estimation of velocity in an open channel. Under steady and uniform flow conditions, we use the Darcy-Weisbach's equation, to compute the section mean velocity carried by a channel section given as

$$
U=\sqrt{\frac{8 g R S}{f}}
$$


where, $g=$ gravitational acceleration, $R=$ the hydraulic mean radius of the channel section, $f=$ the friction factor. Sinuosity and slope have significant influences for the evaluation of meandering channel discharge. The resistance coefficients for the present experimental meandering channels are found to vary with depth, aspect ratio, slope and sinuosity and are all linked to the stagedischarge relationships. The variation of friction factor $f$ with depth of flow for the straight and meandering channels are shown in Fig. 4. The friction factor $f$ decreases with flow depth.

From the Fig. 4, it is seen that the roughness coefficient $f$ is not having similar trend for all the experimental channels. The cause of this may be due to the large variation of hydraulic radius $(R)$ with depth of flow. For the present study, dimensional analysis is carried out to evaluate the variation of roughness coefficients with depth of flow for meandering channels to through more light.

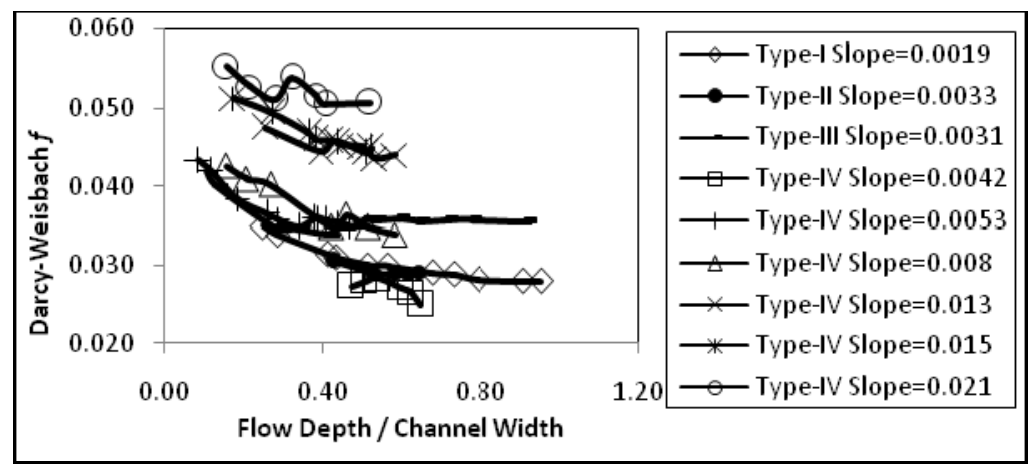

Figure 4: $\quad$ Variation of Darcy-Weisbach $f$ with flow depth.

\section{Dimensional analysis for resistance coefficient}

Dimensional analysis offers a method for reducing complex physical problems to the simplest form prior to obtaining a quantitative answer. The important variables affecting the stage-discharge relationship are considered to be the velocity $U$, hydraulic radius $R$, viscosity $v$, gravitational acceleration $g$, bed slope $S$, sinuosity $S_{r}$, aspect ratio $\alpha$, and it can be expressed functionally as,

$$
\varphi\left\{U, S, S_{r}, \alpha, g, R, v\right\}
$$

Using the equation

$$
U=\left(\frac{8 g}{f} R S\right)^{1 / 2}
$$

and considering its similarity to the traditional roughness coefficient equations, the dimensionless group is proposed as follows

$$
\frac{U R}{v}=\left(\frac{8}{f}\right)^{1 / 2}\left(\frac{g R^{3} S}{v^{2}}\right)^{1 / 2}
$$


where $f=$ Darcy-Weisbach friction factor. As the sinuosity $\left(S_{r}\right)$ is inversely related to the velocity, slope and aspect ratio it is found to be directly related to the velocity. The Darcy-Weisbach equation for one dimensional flow is expressed as

$$
\frac{U R}{v}=\phi\left[\frac{1}{S_{r}}, S, \alpha,\left(\frac{g R^{3}}{v^{2}}\right)\right]
$$

The dimensional group $\left(g \cdot R^{3} / v^{2}\right)$ can be used because of its similarity to the Darcy-Weisbach $f$ (equation 5). Following equation (6), the graph between the dimensionless groups $\left\{\frac{g R^{3} S^{1 / 2}}{v^{2}}\right\}$ vrs. $\left\{\frac{U R S_{r}}{v \alpha}\right\}$ is plotted in Fig.5 using the experimental data together with other available data for meandering channel having different slopes and geometry. A simple relationship between the dimensionless groups is now obtained for a meandering channel of different shapes and under different hydraulic conditions. The best possible relationship is found to be a power function equation having a regression correlation of 0.97 given as,

$$
\left\{\frac{U R S_{r}}{v \alpha}\right\}=k \times\left\{\frac{g R^{3} S^{1 / 2}}{v^{2}}\right\}^{0.86}
$$

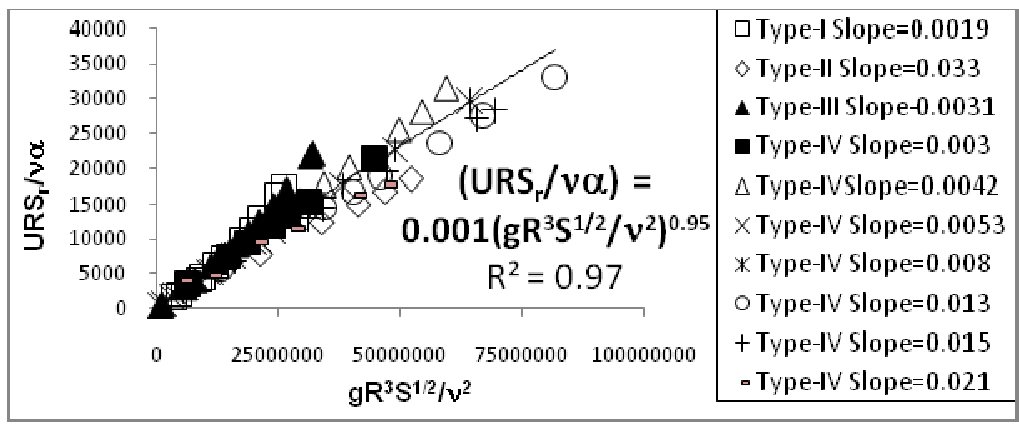

Figure 5: Calibration equation for between $\left\{\frac{g R^{3} S^{1 / 2}}{v^{2}}\right\}$ and $\left\{\frac{U R S_{r}}{v \alpha}\right\}$

Using the relation obtained from equation (5) and equation (7), the developed relationship for Darcy-Weisbach $f$ is expressed as

$$
f=\frac{8 v^{1.8} S_{r}{ }^{2} S^{0.04}}{0.01^{2} \alpha^{2} R^{2.7} g^{0.9}}
$$




\section{Discharge estimation}

For the given geometry of a channel, the values of $f$ are calculated using the equation (8). Then, the corresponding discharge can be easily calculated using equation (3). Now the variation of observed discharge and calculated discharge using (8) and 3 are plotted in Fig. 6.

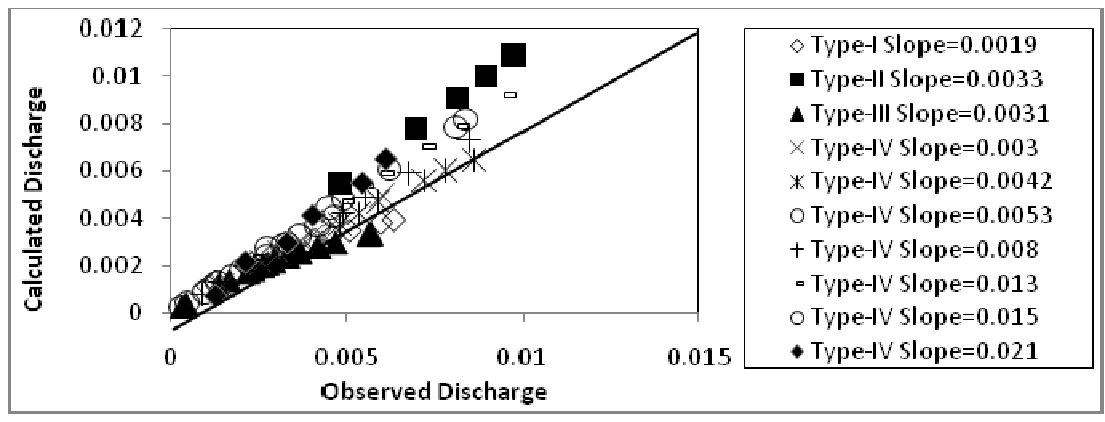

Figure 6: $\quad$ Variation of observed and modeled discharge.

\section{Application of other methods}

Some published approaches of discharge estimation for meandering channels are applied to the present experimental data to know their suitability for such geometry. The standard error of estimation of discharge by the present equation compares well with other investigators as shown in Fig. 7. The overall standard

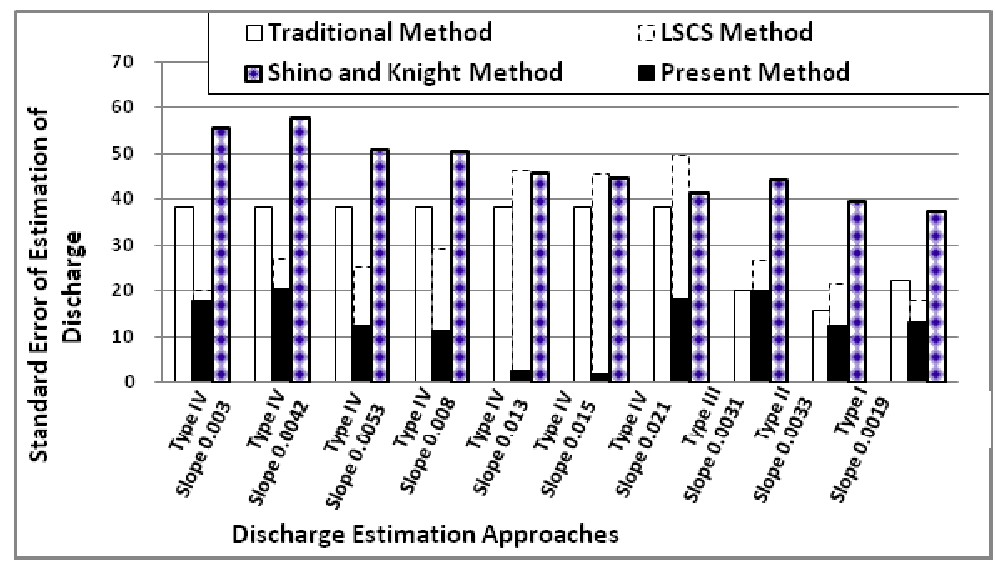

Figure 7: Standard error of estimation of discharge using present and other established methods. 
error of discharge estimation from the proposed method is 14.39 while it is 30.04 for LSCS method and is closely followed by the traditional Darcy-Weisbach's method with standard error of 31.32. The overall standard error of discharge using the Shiono et al. method [19] is also found to be of 46.9. From Fig. 7, it clearly shows that the proposed approach gives better discharge results compared to previous ones.

\section{Conclusions}

*xperiments are carried out to examine the effect of channel sinuosity and geometry on the variation of roughness coefficients in a meandering channel. The study is also extended to a meandering channel of higher sinuosity $\left(S_{r}=1.91\right)$. The flow resistance in terms of DarcyWeisbach friction factors $f$ is found to be changing with flow depth for a meandering channel. The assumption of an average value of flow resistance coefficient for all depths of flow results significant errors in discharge estimation.

* Dimensional analysis has been carried out to predict the resistance coefficients in a meandering channel. These roughness coefficients are found to depend on the four dimensionless parameters namely, sinuosity, aspect ratio, longitudinal slope of the channel, and Reynolds number of the flow. Using the proposed equation for roughness coefficient, stage discharge relationship in a meandering channel can be adequately predicted. The equation is found to give better discharge results as compared to the other established methods.

\section{References}

[1] Arcement, G. J., Jr; and Schneider, V. R. (1989) "Guide for selecting Manning's roughness coefficients for natural channels and flood plains" U.S. Geological Survey Water-Supply paper 2339, Federal Center, Colo.

[2] Barnes, H.H., Jr. (1967) "Roughness Characteristics of Natural Channels" U.S. Geological Survey Water-Supply Paper 1849, Federal Center, Colo.

[3] Chang, H. H. (1983). "Energy expenditure in curved open channels" Hydr. Engrg., ASCE, 109(7), 1012-1022.

[4] Chang, H. H. (1984). "Variation of flow resistance through curved channels", Journal of Hydr. Engrg., ASCE, 110(12), 1772-1782.

[5] Chow, Ven Te (1959), "Open-Channel Hydraulics" New York, McGrawHill Book Co.

[6] Cowan, W. L., (1956). "Estimating Hydraulic roughness Coefficients." Agric. Engrg, 37, 473-475.

[7] "Guide for selecting roughness coefficient "n" values for channels". (1963). Soil Cons. Service, U.S. Dept. of Agric., Washington, D.C. 
[8] "Hydraulic capacity of meandering channels in straight floodways." (1956). Tech. Memorandum No. 2-429, U.S. Army Corps of Engineers, Waterways Experiment Station, Vicksburg, Miss.

[9] James, C. S. (1994). "Evaluation of methods for predicting bend loss in meandering channels." Journal of Hydraulics Engg., ASCE, 120(2), 245253.

[10] James, C. S., and Wark, J. B. (1992). "Conveyance estimation for meandering channels.” Rep. SR 329, HR Wallingford, Wallingford, U.K., Dec.

[11] Jarrett, R. D. (1984). "Hydraulics of high gradient streams" Journal of Hydr. Engg., ASCE, 110, 1519-1539.

[12] Khatua, K. K. (2008) "Interaction of flow and estimation of discharge in two stage meandering compound channels". Thesis Presented to the National Institute of Technology, Rourkela, in partial fulfillments of the requirements for the Degree of Doctor of philosophy.

[13] Lai Sai Hin, Nabil Bessaih, Law Puong Ling, Aminuddin Ab. Ghani, Nor Azazi Zakaria, Mahyau Seng (2008). "Discharge Estimation for Equatorial Natural Rivers with Overbank Flow", Intl. J. of River Basin Management, IAHR, , Vol. 6, No. 1 Pp. 13-21.

[14] Maria, A.A, and DaSilva A. F. (1999). "Friction Factor of Meandering Flows." J. of Hydraulic Engineering, ASCE, Vol.125, No.7, pp. 779-783.

[15] Pang, B. (1998). "River Flood Flow and Its Energy Loss." Journal of Hydr. Engrg., ASCE, 124(2), 228-231

[16] Patra, K.C, and Kar, S. K. (2000), "Flow Interaction of Meandering River with Floodplains". J. of Hydr. Engrg., ASCE, 126(8), 593-604.

[17] Patra, K.C., and Khatua, K. K. (2006), "Energy Loss and Discharge Estimation in Two Stage Meandering and Straight Compound Channel", EWRI of ASCE and IIT Kanpur.

[18] Sellin, R.H.J. (1964). "A Laboratory Investigation into the Interaction between Flow in the Channel of a River and that of its Flood Plain." La. Houille Blanche, No.7, pp. 793-801.

[19] Shiono, K., Al-Romaih, J.S., and Knight, D.W., (1999). "Stage-Discharge Assessment in Compound Meandering Channels", Journal of Hydr. Engg. ASCE vol.125, No.1. pp. 66-77.

[20] Yang, S. Q., and Lim, S. Y. (1997) "Mechanism of energy transportation and turbulent flow in a 3D channel" Journal of Hydraulic. Eng., 123(8), pp.684-692. 